\title{
UTICAJ REAKTIVNOSTI PREDUZEĆA NA EFIKASNOST I EFEKTIVNOST KRIZNOG MENADŽMENTA
}

\section{IMPACT OF COMPANY REACTIVITY ON CRISIS MANAGEMENT EFFICIENCY AND EFFECTIVENESS}

\author{
Darko Arsić, Fakultet tehničkih nauka, Novi Sad
}

\section{Oblast - UPRAVLJANJE RIZIKOM OD KATASTROFALNIH DOGAĐAJA I POŽARA}

Kratak sadržaj - Ovaj rad razmatra odnos između reaktivnosti preduzeća $i$ efikasnosti $i$ efektivnosti kriznog menadžmenta u njemu. Definisana je i razjašnjena efikasnost $i$ efektivnost preduzeća kao i reaktivnost preduzeća tj. osetljivost na promene okruženja, dok je kontrolabilnost atribut sposobnosti preduzeća da kontroliše situaciju kreiranjem organiziacionih uslova (resursa), kao što su fleksibilnost tehnologije, ljudskog resursa, organizacije, organizacione kulture $i$ informacionih sistema.

Ključne reči: Krizni menadžment, efikasnost, efektivnost, reaktivnost, fleksibilnost preduzeća $i$ organizacije, Abstract - This paper examines the relationship between enterprise reactivity and the effectiveness and efficiency of crisis management in it. The efficiency and effectiveness of the company as well as the reactivity of the company were defined and clarified. sensitivity to environmental changes, while controllability is an attribute of an enterprise's ability to control the situation by creating organizational conditions (resources), such as the flexibility of technology, human resources, organization, organizati-onal culture and information systems..

Keywords: Crisis management, efficiency, effectiveness, reactivity, flexibility of enterprises and organizations,

\section{UVOD}

U svim društvima normalan tok života povremeno prekidaju kritične epizode koje su praćene osećanjem pretnje i nesigurnosti - i koje dovode u pitanje način na koji ljudi razumeju svet oko sebe [1].

Takve situacije, koje zovemo krizama, mogu biti uzrokovane prirodnim silama (potresi, cunamiji, olujni vetrovi, bujične kiše, snežne oluje, lavine, epidemije i sl.), namernim akcijama "drugih", to jest različitih neprijatelja unutar ili izvan društva (međunarodni sukobi i rat, teroristički napadi), ljudskim pogreškama u upravljanju tehnologijom, ali njihovi koreni mogu biti i u lošem funkcionisanju sociotehničkih i administrativnih sistema (slomovi infrastrukture, industrijski akcidenti, ekonomske krize i politički skandali) [9].

\section{NAPOMENA:}

Ovaj rad proistekao je iz master rada čiji mentor je bio dr Mladen Pečujlija, vanr. prof.
Uz stare krize koje imaju manje-više poznate uzroke, posledice i vremenske krivulje javljaju se moderne krize pred kojima je ljudski um nemoćan, organizacioni kapaciteti nedovoljni, a javnost egzistencijalno zabrinuta. U nekim pokušajima sprečavanja kriza i njihove kontrole ljudi i njihove organizacije relativno su uspešni, dok su pred nekima nemoćni i mogu ih samo nemo posmatrati pokušavajući ući u njihov zamršeni kauzalitet.

Krize se, uprkos ogromnom napretku ljudskog znanja i moći oličenoj u savremenoj tehnologiji, događaju i danas dovodeći u pitanje kompetentnost ljudi i legitimitet institucija koje nisu sprečile takve destruktivne događaje ili makar umanjile njihove razarajuće posledice [2].

Pred pritiskom navedenih izazova, sve više se razvija krizni menadžment kao nastavno-naučna disciplina i istraživačko polje. Krizni menadžment kao takav se suočava sa vrlo ozbiljnim teorijskim i praktičnim problemima od kojih možemo spomenuti: nejasnoće i dvosmislenost u samom konceptu krize i pokušajima razgraničenja od povezanih i sl. pojmova, zatim koncept kriznog menadžmenta i njegovo razgraničenje od sličnih menadžerskih praksi [3].

\section{PREDMET}

Predmet ovog rada je krizni menadžment u preduzećima. Menadžment je proces planiranja, organizovanja, vođenja i kontrolisanja posla članova organizacije i korišćenja svih raspoloživih sredstava organizacije da se postignu naznačeni ciljevi.

U funkcionalnom značenju on obuhvata zadatke i procese vezane za tekuće aktivnosti preduzeća. Pojedinačno, obuhvata planiranje, organizovanje, implementaciju i kontrolu. Krizni menadžment, zbog karakteristika same krize, ima brojne specifičnosti, jer krizna situacija nastaje neočekivano. Mere za rešavanje krize moraju hitno biti donete a neka rešenja se donose u "hodu".

\section{PROBLEM}

Problem koji razmatra ovaj rad je odnos između reaktivnosti preduzeća i efikasnosti i efektivnosti kriznog menadžmenta u njemu. Prvo je potrebno da jasno defineše šta se u ovoj disertaciji podrazumeva pod efektivnošću i efikasnošću. Adižes (Adiges) je predstavljen kao izvor ovih definicija. Prema njegovim stanovištima organizacije kojima se dobro upravlja su efektivne i efikasne, kako kratkoročno, tako i dugoročno. Postavlja se pitanje sa stanovišta rešavanja ovog problema o značenju reči efikasnost i efektivnost. Postoji mnogo definicija i 
tumačenja ali definitivno ne možemo sa sigurnošću da definišemo oba ova pojma. Uzimajući u obzir prevode i značenja ovih pojmova iz više jezika najprihvatljivije tumačenje reči efektivnost bi bila svrsishodan, koja ne bi predstavljala potpuno tačnu definiciju jer nisu svi svrsishodni sistemi nužno i efektivni. Efektivnost bi mogli tumačiti kao organizovanost ili produktivnost, ali ni to nije potpuno tačno jer organizovanost je samo jedan od načina da se postane efikasan, a nisu svi produktivni sistemi nužno i efikasni. Takođe možemo uzeti i englesko tumačenje ove reči koja bi značila način na koji se izvršava neki proces, meri se broje jedinica koje su potrebne da bi se proizvela jedna jedinica autputa.

Sistem je efikasan ako može da izvršava svoj proces uz najmanju moguću količinu energije. Sa druge strane biti efektivan znači proizvoditi ono za šta je sistem i uspostavljen. Da bi ste postali efektivni, potrebno je da isprobavate različita rešenja dok ne pronađete ono pravo. Stoga, po definiciji, morate činiti ono što mnogi smatraju „greškama", da biste postali efektivni. Ipak, pravljenje izbora podrazumeva pravljenje grešaka, a greške znače rasipanje energije. Da li se može meriti efektivnost organizacije? Mnogi veruju da je prodaja precizno merilo.

\section{HIPOTEZE}

Hipoteze istraživanja su sledeće:

H1: Reaktivnost preduzeća utiče na efektivnost kriznog menadžmenta

H2: Reaktivnost preduzeća utiče na efikasnost kriznog menadžmenta

\section{TEORETSKE OSNOVE}

Prethodnih decenija, mnogi naučnici su se bavili konceptualnim i empirijskim istraživanjem teme velikih ogranizacionih kriza [4]. Razumljivo je da, kao i kod svih novih oblasti istraživanja i ovim studijama je nedostajalo integrisanje (objedinjavanje) [5].

Interdisciplinarna priroda organizacione krize posebno je uticala na nedostatak integrisanog znanja [6]. Specifično je to što su, organizacione krize same po sebi fenomeni $u$ kojima psihološka, sociopolitička i tehnološko-strukturna pitanja deluju kao važne sile koje ih stvaraju i njima rukovode [7]. Pošto studije organizacione krize uključuju mnoge discipline, istraživači veruju da se krize moraju studirati i njima upravljati uz korišćenje sistematskog pristupa [8]. Istraživači veruju da bi psihološka, sociopolitička i tehnološko-strukturna pitanja trebalo eksplicitno razmotriti i integrisati za potrebe izučavanja i upravljanja organizacionom krizom.

Neki naučnici u svojim studijama otvoreno prihvataju multidisciplinarni pristup [9]. Mnogi drugi ipak, analiziraju uzroke, posledice i menadžment organizacionih kriza iz ugla jedne discipline [7]. Rezultat je efekat "Vavilonske kule" gde "postoje mnogi različiti disciplinarni glasovi, koji govore različitim jezicima, o različitim temama i različitoj publici" (Shrivastava1993, str.33) o istoj stvari - organizacionoj krizi. Nedostatak integrativnog pristupa učinio je da se istraživanje organizacione krize nalazi na periferiji teorije menadžmenta.
Da bi se napravio potreban korak unapred prema multidisciplinarnom pristupu u izučavanju ogranizacione krize ([6] u ovom radu razmatraju se gledišta na organizacionu krizu koja su nastala suočavanjem psiholoških, sociopolitičkih i tehnološko-strukturnih gledišta.

U radu nemamo nameru da diskusija o ovim perspektivama bude samo pregled istraživanja u svakoj od oblasti, već da, koristeći perspektive iz svake od oblasti, izgradimo definicije "ogranizacione krize" i "kriznog menadžementa", i da razvijemo sveobuhvatan model procesa kriznog menadžmenta koji oslikava psihološke, sociopolitičke i tehnološko-strukturne pretpostavke.

Kao uvod u prirodu organizacione krize, predstavljeni su u Tabeli 1, primeri različitih tipova krize koji mogu uticati na organizaciju. Brojnost tipova govori o širini ranjivosti jedne organizacije. Iako se čini da se tipovi krize koji su pobrojani značajno razlikuju, kao i sve ogranizacione krize, oni imaju dosta zajedničkih elemenata.

"Sve naše neznanje vodi nas bliže smrti" peva hor u opusu 'Stena' T.S.Eliota.

Izgleda da je uzaludno tragati za tim da li je ova izjava tačna, ali generalno gledajući, sigurno je da neznanje o kriznom menadžmentu dovodi ljude koji su pogođeni nesrećom ili krizom, ne samo na ivicu smrti, već ih često i ubija. Zato je danas bavljenje krizom jedan od glavnih prioriteta tvoraca politika, državnih službenika i izvršne vlasti u preduzećima.

Pored toga, naučna podrška je široka i istraživači krize se slažu da mnogo toga treba da se uradi, da bi se prihvatili budući izazovi u kriznom menadžmentu [5]. U ovakvom kontekstu stalno odsustvo odgovarajuće tipologije kriza i nesreća je posebno bolno [8].

Ako se želi znati kako se različiti tipovi krize razvijaju, koje vrste problema ih okružuju i ono što je najvažnije, kako se sa njima treba boriti, takva klasifikacija bi bila od koristi jer bi identifikovala zajedničke crte različitih kriza. Pored očigledne prilagodljivosti praktičnoj upotrebi, takva tipologija bi dalje mogla da pomogne istraživačima $u$ oblasti kriznog menadžmenta da se suoče sa otporom koji prouzrokuje istovremeno pojavljivanje klasične krize i tzv. post-industrijske, post-nacionalne krize [3] tako što bi se olakšao integrisan pristup različitim krizama.

Klasifikovati krize je kao "pucati u metu u pokretu", pošto budući događaji/nesreće mogu da se razlikuju od ovih današnjih.

\section{REZULTATI ISTRAŽIVANJA}

Iz Tabele 1 možemo videti da je u našem istraživanju učestvovalo ukupno 100 ispitanika.

Od tog broja 32 ispitanika (32\%) pripada preduzećima koja se bave proizvodnim delatnostima dok je ostatak ispitanika (68\%) zaposlen u preduzećima koja se bave uslužnim delatnostima.

Tabela 1: Uzorak ispitanika prema delatnosti preduzeća

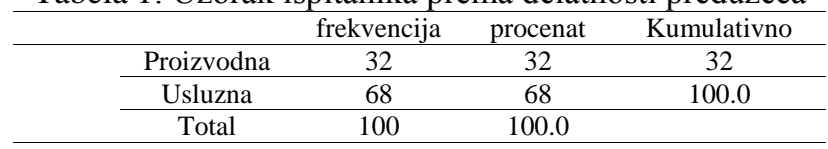




\section{DESKRIPTIVNA STATISTIKA}

Tabela 2: Deskriptivna statistika

\begin{tabular}{cccc}
\hline Promenjiva & As & broj & SD \\
\hline $\begin{array}{c}\text { Procena efikasnosti kriznog } \\
\text { menadžmenta }\end{array}$ & 3.66 & 100 & 1.041 \\
\hline $\begin{array}{c}\text { Procena efektivnosti kriznog } \\
\text { menadžmenta }\end{array}$ & 3.71 & 100 & .999 \\
\hline Afektivna komponenta & 26.02 & 100 & 4.230 \\
\hline Bihejvioralna komponenta & 24.26 & 100 & 4.741 \\
\hline Kognitivna komponenta & 24.18 & 100 & 4.739 \\
\hline
\end{tabular}

Kada se analizira reaktivnost preduzeća može se videti da je najizraženija afektivna komponenta reaktivnosti (26.02) a najmanje izražena kognitivna komponenta reaktivnosti. Ovo ukazuje da u kriznim situacijama da ispitanici više reaguju na afektivnom nivou nego na kognitivnom što umanjuje njihov kapacitet reaktivnosti.

Procene efektivnosti (3.71) i efikasnosti (3.66) kriznog menadžmenta preduzeća u hipotetski kriznim situacijama se međusobno ne razlikuju mnogo - dakle da li se reaguje se na pitanje na adekvatan način i u odgovarajućem pravcu.

\section{Efikasnost kriznog menadžmenta}

Kada se zavisna promenjivu Efikasnost kriznog menadžmenta podvrgne analizi uticaja manifestnih nezavisnih promenjivih iz tabele regresione analize (Tabela 6) može se videti da su sledeće manifestne nezavisne promenjive signifikantni prediktori efikasnosti kriznog menadžmenta:

- Afektivna komponenta $(0.085,0.038)$

Tabela 3: Prediktori efikasnosti kriznog menadžmenta

\begin{tabular}{cccccc}
\hline \multirow{2}{*}{ Model } & \multicolumn{6}{c}{$\begin{array}{c}\text { NestandardizovaniStandardizovani } \\
\text { koeficijenti }\end{array}$} & \begin{tabular}{c} 
koeficijenti \\
\cline { 2 - 5 }
\end{tabular} & $\begin{array}{c}\text { Stand. } \\
\text { Gr. }\end{array}$ & Beta & & \\
\hline Konstanta & .947 & .203 & & 4.660 & .000 \\
\hline $\begin{array}{c}\text { Afektivna } \\
\text { komponenta }\end{array}$ & .021 & .010 & .085 & 2.075 & .038 \\
\hline $\begin{array}{c}\text { Bihejvioralna } \\
\text { komponenta }\end{array}$ & .009 & .011 & .042 & .842 & .400 \\
\hline $\begin{array}{c}\text { Kognitivna } \\
\text { komponenta }\end{array}$ & .016 & .011 & .072 & 1.498 & .135 \\
\hline
\end{tabular}

Ispitanici obuhvaćeni istraživanjem smatraju da će krizni menadžment biti efikasniji ako je u organizaciji izraženije liderstvo, ako postoji dostupnost informacija, ako su zaposleni optimalno raspoređeni po radnim mestima i ako je njihova reaktivnost pna kriznom situaciju pre svega afektivne prirode.

Dakle, u preduzećima koja su obuhvaćena istraživanjem ne postoji koncept učenja reagovanja u kriznim situacijama, ne postoji izražen koncept angažovanja zaposlenih u kriznim situacijama niti izražena svest i volja o takvoj potrebi.

\section{Efektivnost kriznog menadžmenta}

Kada se zavisna promenjiva Efektivnosti kriznog menadžmenta podvrgne analizi uticaja manifestnih nezavisnih promenjivih iz tabele regresione analize (Tabela 7) može se videti da su sledeće manifestne nezavisne promenjive signifikantni prediktori efikasnosti kriznog menadžmenta:
Tabela 4: Prediktori efektivnosti kriznog menadžmenta

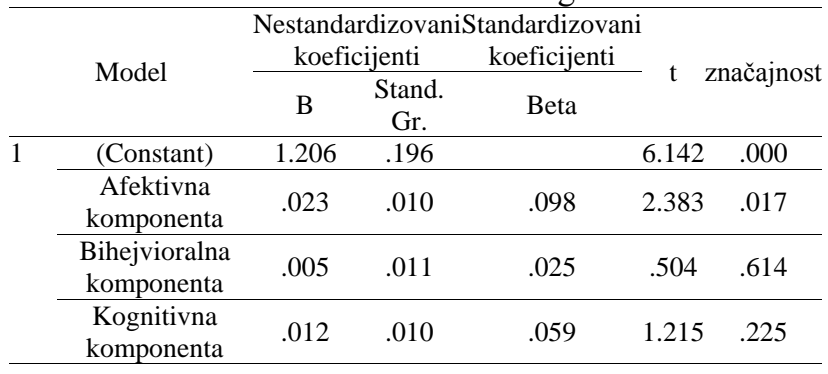

Ispitanici smatraju da će krizni menadžment biti efektivniji ako u organizaciji postoji dostupnost informacija, ako su zaposleni optimalno raspoređeni po radnim mestima i ako je njihova reaktivnost na kriznu situaciju pre svega afektivne prirode.

Dakle, u preduzećima koja su obuhvaćena istraživanjem ne postoji koncept učenja reagovanja u kriznim situacijama, ne postoji izražen koncept angažovanja zaposlenih $\mathrm{u}$ kriznim situacijama niti izražena svest i volja o takvoj potrebi

\section{DISKUSIJA}

$\mathrm{S}$ obzirom da je istraživanje po svojoj prirodi eksploratornog karaktera može se zaključiti da se dobijeni rezultati ne uklapaju u teoretske postavke kriznog menadžmenta i da je pre svega u firmama koje su bile obuhvaćene istraživanjem svest o kriznom menadžmentu na vrlo niskom nivou.

Ovu pretpostavka je potkrepljena pre svega time što rezultati ukazuju da ispitanici opažaju reaktivnost kao bitnu komponentu za efektivan i efikasan krizni menadžment ali, ta reaktivnost je pre svega izražena kod obuhvaćenih ispitanika na afektivnom nivou. Dakle, u pretpostavljenoj kriznoj situaciji ispitanici smatraju da je najbitnije reagovati na emotivnom nivou.

Krizne situacije kod njih bude pre svega emocionalne reakcije koje deluju inhibitorno na saznajnu i voljnu komponentu njihove reaktivnosti tako da je primarna reakcija u kriznim situacijama tipa Spasavaj se ko može $i$ kako zna ume. Oni su potpuno nepripremljeni i nemotivisani za angažman i spas se najčešće očekuje od nekih instanci koje su van njihovih preduzeća ili se ponašaju tako da ih samo vođe mogu spasiti.

Dakle, u firmama koje su bile obuhvaćene našim istraživanjem možemo govoriti samo o kriznom menažmentu reaktivnog nivoa i kod nas nema ni govora o tome da preduzeća funkcionišu na nivou aktivnog kriznog menadžmenta, to jest da se bave predviđanjem mogućih kriznih situacija i kreiranjem planova za reagovanje. Stepen pripremljenosti organizacije na krizu može se klasifikovati u pet nivoa gde je prvi nivo najmanja pripremljenost, a poslednji dobra pripremljenost.

Između njih, uopšteno posmatrano, svaki naredni nivo uključuje sposobnosti za upravljanje krizom sa prethodnog nivoa, ali i neku dodatnu snagu odnosno prednost. 


\section{ZAKLJUČAK}

Na osnovu dobijenih rezultata može se zaključiti:

1. Krizni menadžment u preduzećima koja su bila predmet istraživanja je slabo razvijen

2. Ispitanici u kriznim situacijama reaguju pre svega na afektivnom nivou

3. Kod ispitanika je formiran stav naučene bespomoćnosti u kriznim situacijama $\mathrm{s}$ obzirom da dimenzije fleksibilnosti preduzeća (aktivno učešće i učenje) nisu sastavni deo strukturnog modela povećanja efektivnosti i efikasnosti kriznog menadžmenta

4. Reagovanje na krizu i sam krizni menadžment u preduzećima koja su bila predmet istraživanja je REAKTIVNE PRIRODE

5. U preduzećima treba jačati ANTICIPATORNI pristup kriznom menadžmentu

6. U preduzećima treba jačati fleksibilnost kroz jačanje komponente UČENJA I ANGAŽMANA

\section{LITERATURA}

[1] Acquier, A., Gand, S. and Szpirglas, M. (2008), 'From Stakeholder to Stakeholder Management in Crisis Episodes: A Case Study in a Public Transportation Company', Journal of Contingencies and Crisis Management, Volume 16, Number 2, pp. 101-114.

[2] Browne, M. (1989.) Oil on surface covers deeper threat. New York Times, March 31: 12.
[3] Brunet, S. and Houbaert, P. (2007), 'Involving Stakeholders: The Belgian Fowl Pest Crisis', Journal of Risk Research,Volume 10, Number 5, pp. 643-660.

[4] Deal, T. E., \& Kennedy, A. A. (1982.) Corporate cultures. Reading, MA: Addison-Wesley.

[5] Frazer, J.G. (1922), The Golden Bough, Macmillan Publishing Company, New York.

[6] Roberts, K. (1993.) New challenges to understanding organizations. New York: Macmillan.

[7] Seymour, M. and Moore, S. (2000), Effective Crisis Management, Continuum, London.

[8] Shapira, Z. (1995.) Risk taking: A managerial perspective. New York: Russell Sage Foundation.

[9] Shrivastava, P. (1987.) Bhopal: Anatomy of a crisis. New York: Ballinger.

\section{Kratka biografija:}

Darko Arsić rođen je u Loznici 1967. godine. Fakultet elektrotehnike - energetski smer završio je na Fakultetu Elektrotehnike u Tuzli 1992. godine. Dugogodišnji je član inženjerske komore Srbije i bavi se projektovanjem i izvodjenjem u elektrotehnici. Trenutno je student master studija na studijskom programu Upravljanje rizikom od katastrofalnih događaja i požara. 